\title{
Adapting Cities for Mediterranean Migration Influxes: The Arrival City
}

\author{
Omar Salem \\ Department of Architecture and Urban Design, German University in Cairo, Cairo, 11835, Egypt
}

Received November 1, 2020; Revised March 21, 2021; Accepted March 29, 2021

\section{Cite This Paper in the following Citation Styles}

(a): [1] Omar Salem, "Adapting Cities for Mediterranean Migration Influxes: The Arrival City," Civil Engineering and Architecture, Vol. 9, No. 3, pp. 760-769, 2021. DOI: 10.13189/cea.2021.090317.

(b): Omar Salem (2021). Adapting Cities for Mediterranean Migration Influxes: The Arrival City. Civil Engineering and Architecture, 9(3), 760-769. DOI: 10.13189/cea.2021.090317.

Copyright $(2021$ by authors, all rights reserved. Authors agree that this article remains permanently open access under the terms of the Creative Commons Attribution License 4.0 International License

\begin{abstract}
Migration was and still is one of the main topics repeated continuously throughout history and studied by scientific communities. Yet, studies have been lacking the relation between migration and the urban fabric of a city, either in terms of preparedness or as an impact. Migration should not be seen entirely as a socio-economic issue; the pressure this creates on land resources and its impact on the urban fabric needs to be as well taken into consideration. In the scope of migration, one would always find two types of cities; departure cities where the efflux arises and arrival cities receiving the influxes. Certainly, both types of cities are positively and negatively affected by migrations. In the Mediterranean basin, the origin of so many cultures based on the mobility of their inhabitants, the current socio-economic and political instability in the MENA region, contributed to a massive influx of migrants to European cities for many reasons including, but not limited to, its proximity and the relatively high livelihood quality. This particular phenomenon obliges us to question the time-being used methods to deal with the present extensive influxes and to rethink new city planning approaches towards a resilient Arrival city. This paper demonstrates the case of European Arrival cities; definitions, characteristics, as well as the urban, socio-economic and political adaptations for the current overflowed migration influxes. The demonstration and discussion should be primarily seen as a catalyst that does not only promote for a healthier absorption in choked cities impacted by migrations but intensify the vital role of states, urban planning and resilience in shaping satisfactory conditions for fruitful development impacts of migrations to exist in such cities.
\end{abstract}

Keywords Migration, Mediterranean, Arrival City, Urbanism, Socio-economics

\section{Introduction}

Societies that settled around the Mediterranean tended to have a strong degree of acculturation because of the mutual atmosphere, topography, and access to the sea. Unlike any other time, the Mediterranean today represents a cultural, economic and geopolitical space that separates the European nations from the rest of the Mediterranean countries. It is a gap between the first and third world countries, in which migrants are willing to risk their lives crossing, to seek better life conditions.

The improved living standards, higher levels of education and technological advancements in the European countries acted as pull factors for migration. On the other hand, the recessive economic situation fueled by political instability and undermining human rights in the MENA region, contributed to extensive migration influxes to Europe and in particular Mediterranean port cities, the gates of Europe.

The present Mediterranean migration phenomenon is very different. The present scenario in Europe is more complex, especially in countries bordering the Mediterranean, where the social, economic and demographic crisis is subtle and seems irreparable. The migration pressure on Europe from the Near East and Africa has been excessively ascending, possibly exceeding the European countries' absorption capacity. 
Most of the immigrants to Europe are either asylum seekers or individuals, in some cases with their family members, seeking better livelihood conditions.

One of the substantial talks about migrations and refugee crisis was hosted and covered by an architectural journalist Marcus Fairs in Dutch Design Week 2017, under a series titled "Good Design for a Bad World." During that discussion the panelists mentioned; "Designers should stop proposing gimmicky solutions to the refugee crisis such as shelters, apps and emergency clothing. Instead, efforts should be made to shift the negative narrative around population movements and to help make cities be able to absorb incomers better" [1].

Michelle Provoost, an architecture historian of Crimson Architectural Historians, pointed out in the same discussion that people movements have been there for ages and are impossible to prevent. She argued that instead, integrating migrants should be seen as a planning issue. "This is an issue directly related to spatial design and urbanism" [2], Provoost argued. In addition, she provoked another issue questioning the preparedness to deal with the influx and efflux to and from cities. She claimed that the way to integrate newcomers and asylum-seekers is to provide them with jobs and houses. This way, they can contribute to economic growth. However, spatially they are excluded from doing as such. Thus, there is undeniably a spatial issue related to this.

\section{The Arrival City}

Since Arrival cities' diversity is one of the primary elements impacted by migration, integration processes need to be planned ahead. Fruitful integration involves strategies, which address the whole public, including the natives and migrant communities. The transformation of cities must be collective; not only focusing on particular classifications of individuals, either the elderly, children, migrants or refugees. Cities should have higher levels of resilience along with the ability to deal with contrasts. By joined efforts and intergenerational procedures, cities should plan well ahead of time for an integration strategy, to guarantee upon the arrival of refugees and/or migrants in the city, it is brought into effect.

The capacity of cities to recognize and achieve their specific goals and objectives requires resilient and action-oriented leadership capabilities, which continuously respond and adapt to changes in an aim to reach comprehensible migration strategies. Several cities that were only used to be stepping-stones to the European continent have become destination cities in the present, which has implications for policy and resources. The following chapters will be discussing the terminology and characteristics of arrival cities as well as addressing how the successful ones handle the migration scenarios. In almost any scenario, it is vital to empower social cohesion and not to estrange the native population. Strategies need to be adaptable to readjust to evolving conditions, and working relationships should be built on both levels; the state and the respective community. The overall economic growth and development will be significantly affected by strategies that cities oversee to manage migration.

As a result of the large influxes of immigrants and/or refugees, critical challenges to urban administration, urban planning and design in many European cities have arisen. Questions for urban communities have emerged, such as how to help, train, house, and integrate individuals from different cultural backgrounds [3].

Relocation has turned into an unavoidable fact; a city should adapt to large influxes. Newcomers ought to be welcomed in an imperative zone where there are work and integration opportunities. According to Nadia Pepels, an Architect, the Arrival city is where the transformation of the modern ruin turns into a transit place for wide range newcomers. The basic necessities to Pepels include a variety of housing with vast opportunities for business, arrival services, and cultural and social integration. She claimed that since we don't know the needs and desires of all the diverse immigrants, with temporary characters (fast coming and going of people), we should design for the unexpected using flexible design tools [4].

\section{Definitions of Arrival Cities}

Over the last decade, the world witnessed a massive increase in migration levels, leaving researches and writings about arrival cities to rapidly grow into a hotspot contemporary topic. In 2015, Ada Colau, the Mayor of Barcelona, claimed that the current situation in Arrival cities should be analyzed from different perspectives; she stated: "it may be that states grant asylum, but it is cities that provide shelter" [5] while launching the Barcelona Refuge City action plan. This plan was in response to the crisis, preparing the city to support and receive refugees by protecting their legal rights, providing them with essential services, and addressing states to respect the basic livelihood standards of humanitarian laws.

Arrival cities, from a social and cultural perspective, has been for quite some time perceived as urban areas, usually large ones, where cultural diversity thrives. It embodies the social, cultural, and religious diversity that numerous people believe is a fundamental characteristic of regions that will socially and economically flourish in an era of global interdependence [6].

On the other hand, from an economic perspective, the Arrival city was defined as a set of immigrant networks and calculated investments in an urban future [7].

Doug Saunders, a journalist and writer, in his book Arrival City defined an Arrival city as a place or district where immigrants end up right after immigrating. He addressed how they utilize the infrastructure, resources, individuals and the impact of all these combined on the 
long-term success of a family. According to Saunders, the basic rule of the Arrival city is that those emigrating from poorer nations cannot afford to live where their destination is. Almost under all circumstances except war resettlement, the people who immigrate to cities do so because of higher incomes opportunity.

In another chapter of his book, Saunders explained that it is more accurate to define the Arrival city by its functions. It is the hotspots where tight social networks erupt, usually of people from the same geographic region, providing basic services such as cheap housing and facilitate finding entry-level occupations.

So, within the previous framework what is an Arrival city? It can take the form of a neighborhood, a slum, a suburb or an exurb; what is essential, is more the function of the space rather than its physical form. It was referred to Arrival cities as points of arrival for new migrants, where they connect to the existing networks of friends and families to start building their new urban lives. Alternatively, a transitive place where immigrants temporarily settle to develop themselves economically and socially before integrating into the native population [8].

Saunders brought out the term Suburbanization of the
Arrival city when a shift from the central city to the suburbs occurs; as many of the urban neighborhoods are no longer affordable for newcomers. A standout element of addressing our presumptions is Saunders shouting out that we should recognize less developed arrival cities not as indecent traps of poverty, but as transition areas where the very poor gain a foothold in the city, gearing up to the middle class. "These transitional spaces - arrival cities are the places where the next great economic and cultural boom will be born, or where the next great explosion of violence will occur. The difference depends on our ability to notice, and our willingness to engage" [8].

\section{Characteristics of Arrival Cities}

In the recent years, a research conducted in Studio Arrival City (a MArch Design Studio at Sheffield School of Architecture) investigating the "physical characteristics of the Arrival cities" [9], referring to Arrival City book written by Doug Saunders. The research was completed by analyzing selected case studies to explore any consistent phases of development the arrival city may experience over time.
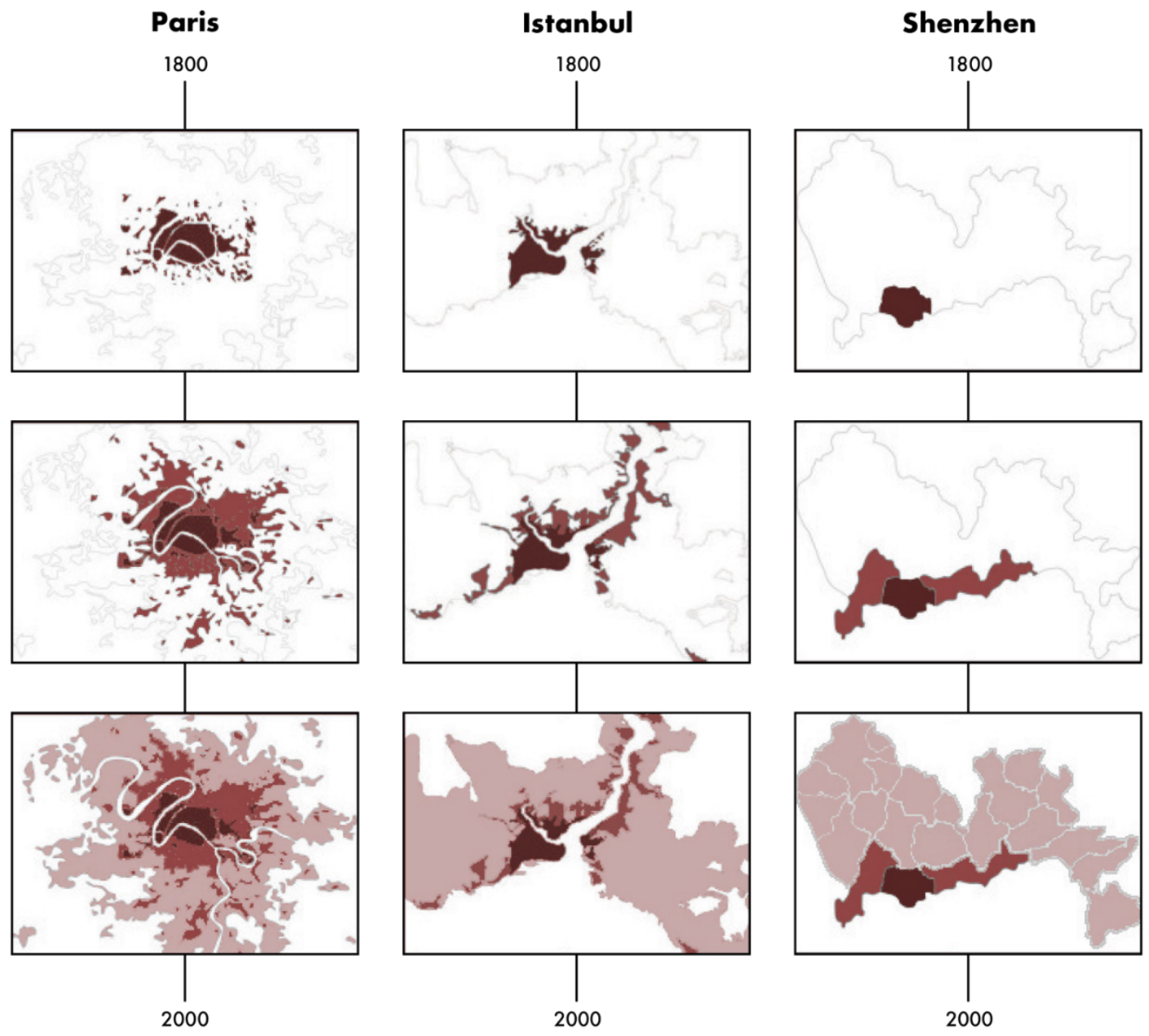

Figure 1. Phases of Development in Arrival Cities 
The following lines are summarizing the three case studies (Paris, Istanbul and Shenzhen) used in this investigation showing their development between the years 1800 and 2000, as shown in (figure 1), in order to understand some of the characteristics of these main cities.

\section{Paris}

1800 -

After introducing global commerce restrictions at the end of the 18th century and France went thorough food shortages, Paris witnessed a significant increase in population. Whilst the wealthy and stable urban class occupied the lower floors of Parisian buildings in stable conditions, the new arrivals often had to share windowless rooms on the upper floors. Only one of those rooms could accommodate even a dozen people, who are often working at all hours in deplorable conditions. This upraised the rural city residents and eventually led to the industrial Revolution.

\section{- 1900 -}

Years later, the city has undergone massive urban changes by Eugéne Haussmann who designed larger streets that improved the circulation around the city and Haussmann Boulevard, which was initially constructed to squash any hind of coups or another revolution. In the new urban design scheme, unhealthy neighborhoods were replaced by introducing parks, squares and large avenues. Paris was redesigned into a well-organized urban center, and naturally, this attracted even more villagers and migrants to move to the city. But eventually, the urban core had reached its capacity and migrants had to move to surrounding neighborhoods seeking cheaper rents and larger spaces.

\section{$-2000$}

One of those neighborhoods is Bellville, which started during the Second World War by attracting Jews. In the post-war period many musicians and artists were attracted to the city, and eventually Africans, Asians and Europeans. In the present, it is a successful Arrival City neighborhood well connected by tram and Metro, housing one of the two Chinatowns, and diverse restaurants. It boosted the education system and public spaces overlooking the narrow streets, opened to the ground floor creating a great social cohesion opportunity.

\section{Istanbul}

$1800-$

In the mid-1850s when the alliance (Ottomans together with France, Sardinia, and Italy) won against Russia in the Crimean War, the Ottoman Empire drove a moderate movement towards modernization, which eventually led to a more significant Western impact on the urban typology of Istanbul. Thus, the city witnessed many transformations featuring boulevards, avenues and turning into a reflection of the colonial mode. The Western Architectural style began to invade the city especially when warehouses and docks were introduced due to imperatives of trade and technology. Till 1912-1913, non-Muslims dominated Istanbul forming a new demographic profile.

- 1900 -

Istanbul witnessed an extensive influx of Muslim refugees after many Christians fled the city following the Balkan Wars. Even prior to the war, in 1909 some Christians had to departure due to the institution of universal conscription obliging non-Muslims to pay a tax. Eventually, that led to a sudden change and shrink in the city's population forming pockets within the inner city, which would gradually turn into unhealthy neighborhoods by new arrivals. One of these neighborhoods is Gecekondus; dense, illegitimate, informal dwellings constructed by new arrivals towards 1950 when the city became less permeable. It began to grow bigger, informally around the periphery and it was only in the 1970s when it was legitimized by the government. On the other hand, the city witnessed an increase in the middle class who parceled former Ottoman estates along the waterfront (Bosporus Strait) and the edge of the city. But gradually in the 1980s, the Gecekondus like other informal neighborhoods became unsustainable due to the lack of funding for public services.

\section{$-2000$}

By the 1980s and 90s, it was a turning point for the urban tissue of Gecekondus and its relation to the urban fabric. Developers purchased part of the neighborhood developing commercial districts and gated communities lacking urban connection to their surroundings.

\section{Shenzhen}

\section{$1800-$}

The origins of the Chinese city back to a small fishing village named Baoan County populated by 30,000 inhabitants. It was well known for the salt industry, and its future key potential relied on its location with access to trade via the Pearl River sharing a border with what was to be become the city of Hong Kong.

\section{- 1900 -}

In 1979, the Chinese government declared the village as Special Economic Zone (SEZ) an area with special trade and business laws, different than the rest of the country. That decision did not only trigger an increase in job creation, investment, and trade, but rapid economic growth as well accompanied by urban development. The core districts of the SEZ became dramatically intensified by these developments, affecting the urban fabric. The 
whole urban fabric situation changed from a small fishing village to a densely populated core for economic activity. Later, it was given the name "Shenzhen" (derived from drainage ditches) because of a belief that flowing water encompassing the city would grant solid flows economic prosperity to the city throughout the newly designated SEZ.

\section{$-2000$}

During the new millennium, the rapid economic growth of Shenzhen continued in parallel to the development of the city, creating a new economic giant monster. The success of the SEZ and the continuous development of the city led to an excessive mass internal migration. When the influx increased, new arrivals started to fill the voids in the city like in many other arrival cities, leading to further intensification of the new city. In 2010, the great majority of the population boom in Shenzhen took place when the surrounding neighborhoods were absorbed into the SEZ. While in other arrival cities a mass sprawl is most probably to occur, Shenzhen was different and succeeded in its expansion through the absorption of existing districts and developing them accordingly.

Results from the previous analysis demonstrated three variations of the Arrival city:

\section{A. Intensification - Filling the Void:}

In many different ways throughout the centuries, Arrival cities' first reaction to a boom in population is to fill existing voids within the urban fabric. There are three approaches for intensification: 1) dividing the large monumental buildings to create more vacancies, 2) fill vacant properties in core districts, or 3) boost high rise construction within core districts to increase its urban density.

\section{B. Separation-Creating the Peripheral City:}

After arriving population saturates the core districts, the second stage is often to create the peripheral city. Although these peripheral cities often have a unique identity, they still have an influence on the established cities; this can be seen with the creation of slums or the development of the outer districts to the city. Initially, this was how the notion behind an Arrival city preconceived; an entity established exclusively for new arriving population, which is later, used to feed into an established city.

\section{Absorption - Merging the Arrival \& the Established:}

These peripheral districts are usually absorbed into the already established city. The absorption often happens through gentrification or an overwhelming and exaggerated expansion of core districts to an extreme point where they engulf their surroundings. From this stage, it is highly arguable that the whole process repeats itself again as core districts expand further, creating more voids awaiting to be filled, and stimulate another phase of sprawl thereafter.

Unlike the previous tangible variations, the Deutsches Architekturmuseum (DAM) in close collaboration with Doug Saunders developed eight theses on the Arrival city at the International Architecture Exhibition 2016, following the arrival of more than one million refugees from 2015 to 2016 in Germany. "Eight theses on the Arrival City" intends to deliver the intangible image of an Arrival city through addressing a critical question at that time; from an architectural and urban planning point of view, what are the conditions that should exist in Arrival Cities to grant successful integration of immigrants in Germany [10]. The Arrival City is:

1. "A City within a City" Immigrants usually target areas of high urban densities where there are more opportunities. At some point, immigrants flock to one area in large numbers forming districts or neighborhoods with their identity. These neighborhoods are often problematic areas, but still, hold much to offer to new arrivals.

2. "Affordable" Cities need to meet housing unit demand from new arrivals and look for ways to be attractive enough for immigrants. The latter can be achieved through encouraging inexpensive housing, lower rents, low-cost life and limiting property speculation.

3. "Close to Business" Most immigrants take part in economic life and they often move to the cheapest neighborhood they can find when they arrive in a new city. And as Saunders stated "jobs emerge where there are already jobs" which are often in denser centers, the city indeed needs a convenient public transport system.

4. "Informal" Arguing for leaving a margin for flaws and tolerating semi-legal business practices. In this sense, it is meant that business practices, labor, and licensing restrictions are partially ignored.

5. "Self-built" Immigrants need to have a sense of belonging and ownership of their home. They need to feel that they exist, integrate and take part in designing and/or building for themselves. In this direction, building codes and construction regulations should not necessarily delay muchneeded self-built solutions.

6. "On the Ground Floor" Many new arrivals open their own small businesses with diverse background origins trying to climb up the social ladder. The availability of such spaces on the ground floor determines the level of success in a neighborhood.

7. "A Network of Immigrants" Enabling community and support networks in community spaces like a mosque or through ethnically homogenous districts.

8. "Needs the Best Schools" Arguing for high quality learning environment and education services that everybody wants to send their children to. Migrant children and foreign-born should compete with 
middle and highly educated class children. Arrival cities should ensure a better future for children.

\section{What Makes an Arrival City Successful?}

The present urban growth generally, and through migration mainly, acquires greater complexity of urban development and its interrelation with the population as a whole. Migration significantly affects multiple sectors for example, housing, infrastructure, transportation, education, health, water and sanitation, the environment, utilities and services, crime rate and social cohesion. Due to migration, for instance, the fundamental infrastructure and basic service provision have been subject to higher demand levels. And so, this chapter will be referring to what academics and professionals believe can make an Arrival city successful.

\subsection{Infrastructure, Utilities and Services}

As a fundamental booster for human development and flow (of people, goods and information), infrastructures should meet basic requirements in order to facilitate accessibility to workplaces, markets, terminals, educational and medical services. These shall be the catalysts to boost the economic growth, facilitate the monetary movements and drive the prosperity of a city.

Integrating immigrants into a society heavily depends on the level of access to transport, which facilitates the interaction between people within a community, access to educational opportunities and city services, carrying out trade, and get to see and participate in things outside of their own neighborhood scale [11].

Cities need to:

- Guarantee a sustainable, safe, and affordable accessibility to transport systems by all levels of society. The previous should be done along with refining the safety of roads, notably by scaling public transport and the infrastructure to meet the transportation demand, putting into consideration the needs of those in vulnerable situations, for example (the elderly, children, women, and disabled people), as a priority.

- Engage the private sector to collectively tackle new funding techniques to implement mega scale infrastructure and transportation projects.

- Bring academic institutions and think tanks into operation by capitalizing on their researches towards a positive future of human mobility and effective transportation planning.

Another crucial policy the government should focus on, beyond the language proficiency or the sense of ownership, is to prevent the isolation of immigrant settlements; they must be connected to the neighboring districts through a network of pathways and appropriate levels of facilities. Or else, we might end up with a satellite town lacking suitable transportation links to the center of the city [12].

However, Mehaffy, an architectural theorist, urban philosopher and executive director of the Sustasis Foundation, argues that this is contradicting what is happening while urbanizing parts in the developing cities today. "But this is far from conventional urban practice, which too often features an art-dominated approach to architecture, that values novel visual imagery over enduring human city-making" [13]. This strategy, at its worst, more or less dominates a sort of advertising packages over an on-going mechanical way to deal with urban communities: focusing on objects, promoting gated communities, dehumanization, building superblocks and malls, besides the over-dependence on high-resource consumption systems like individual automobile transportation.

\subsection{Housing}

Cities are racing in tension against time to provide accessible financially reasonable social housing that fulfils design, safety standards, and most importantly, a short delivery time, for migrants as well as for the growing local population.

Cities need to [14]:

- Find practical and quick solutions to solve the lack of social and/or affordable housing. In some cases, failing to find such policies might force migrants to meet their own needs and resulting in overcapacity and development of slums.

- Engage the private sector and multi-stakeholders in financing housing projects.

- Develop policies granting an optimum land-use for city housing projects.

- Initiate a city-scale analysis to re-use unoccupied spaces, flats or less-used buildings, for long or short-term housing projects to meet the demands of migrants and locals.

- Scale their transport infrastructure and strengthen public transport so that migrant workers can stay in dispersed locations throughout the region, yet still, easily reach job opportunities everywhere.

Regarding the needs for housing solutions for immigrants, there are several points of view that might be contested or not. In his point of view, Saunders argues that one of the key elements to solve the lack of affordable housing issue is to have both, an open market with an active engagement of the private sector to provide properties, besides a robust forceful government prepared to heavily spend on migrants, with the latter being more dominant [8].

Another point of view by Scheuermann, an architect, and freelance curator, suggests that accommodations 
should not necessarily be perfect - but rather cheap. It must be open, with smaller rooms, and common spaces to allow people to build their own social network, and engage with other people who share a common language, traditions or religion [15].

Migrants often want to move into better houses after a measure of time, yet still, they do not want to live in another neighborhood. In this case, it may be reasonable to replace some of the older houses with newer ones, which is suitable for the emerging new middleclass. It might be logical as well in the cases of buildings with very poor conditions, or a relatively high vacancy rate. Be that as it may, many professionals are against following this physical approach when it is just intended to reorganize the area into a regular one. By the time, it will often reach the point where it is neither fish nor flesh [12].

\subsection{Education and Employment}

With growing populations and the on-going budget cuts in some areas, education systems became subject to tremendous pressure. Contingent upon their abilities, cities need to be resilient enough to quickly improve their situation by scaling-up and improving their educational assets, training and employing a new highly skilled staff. The metaphor of a primary school refers to the importance of having the 'school' properly equipped with high-skilled educators and an airtight building in order to function well.

An Arrival city should pay special attention when dealing with a diverse community. Besides the issues of managing capacities and financing, cities as well need to outlaw segregation in schools, assess the knowledge and skills of newcomers to match them accordingly with the labor market, and guarantee them an effortless transition between welcome classes and regular schooling.

In order to achieve this, the government need to [16]:

- Avoid segregation (where we can find a high number of migrants concentrated in a lower number of schools, which are often not mixed with many of the local population) and allocate migrants in different schools across the neighborhoods of the city.

- Encourage learning institutes and their staff to join forces with other key-players in the society, such as reconciliation and integration services, on identity-related activities and job developments for migrants.

- Narrow the gap between proper education and being into the workforce; whenever immigrants or inexperienced poorly educated labor settle in destination cities, they favor money on education, so they start to search for work instead of finishing their education.

Since education is a key-element for the success of Arrival cities, cities should as well upgrade education facilities and increase their number to meet the demand from both, the locals and newcomers. Governments should provide peaceful, comprehensive, and effective learning environments that are child, disability, and gender sensitive. Beyond the quality and accessibility of educational and vocational programs, a city should introduce affordable opportunities for all, locals and newcomers [17].

However, Helleman argues that although all citizens are equal, we should leave room for differences to some extent in order to achieve effective labor market policies, because disparities in the labor market are mostly generated by contrasts in education and employment possibilities [12].

Cities that follow urban strategies, which facilitate the process of issuing their work permit are often viewed internationally as successful examples. Some cities provided all their newcomers with identification cards to allow them to participate in the economic and social discourse, such as granting them the right to open bank accounts in order to access the city services.

These strategies require collaboration with local employers and should include efforts to match newcomers with jobs. Policies should pay special attention to potential new immigrant entrepreneurs and facilitate the process for start-ups. This could be achieved through connecting them to former entrepreneurs, local suppliers, and potential partnerships. Creating these attractive environments for start-ups will draw ingenious entrepreneurs from outside the country and inspire the newcomers [18].

Therefore, Arrival cities need to integrate newcomers in the employment sector through:

- Initiating awareness campaigns for the locals to promote the benefits of hiring migrants to business entities and civil society organizations.

- Minimizing the logistical and bureaucratic pressures on entrepreneurs by ensuring fair processes equally accessible to whoever meets the criteria, regardless of being a local or a migrant.

\subsection{Health}

Accessibility to healthcare services is a crucial contribution to the socio-economic development of an Arrival city. Therefore, such cities should aid migrants in overcoming the linguistic and cultural and linguistic barriers, deliver equally accessible healthcare and ensure the well-being of immigrants and/or refugees.

And this can be achieved through the following [19]:

- Developing policies that ensure equity of healthcare access and affordability to migrants, paying special attention to vulnerable war refugees. In addition to planning a satisfactory healthcare system, which provides a fair distribution of healthcare services among the city to cater to the migrant population. 
- Initiating awareness campaigns for immigrants to let them know their rights, as well as the accessible healthcare in the city available to them.

- Engaging multi-stakeholders in revising the existing policies, deliver healthcare services in new forms and methods, for example, health camps or online clinics to discuss with the immigrants the matters directly affecting them.

\subsection{Water and Sanitation}

In general, urbanization is always accompanied by particular rising challenges relating to the management of resources, particularly water and energy. The growing populations in metropolitan cities mean the consistently expanding need for water and newer sanitation techniques, which are not usually present locally.

In the previous sectors, long-term housing and educational requirements in cities have been addressed, but one should be aware that these as well raise major concerns to meet the rising demand of water and energy as an integral part of the development process. Cities must provide sufficient energy to power each private dwelling and public property, in addition to meeting the daily demands of safe drinking water and ensure its accessibility to temporary dwellings, slums and refugee camps.

The following opportunities would facilitate reaching the previous targets [20]:

- Implement ecological high-tech water management systems to cover all satellite towns, temporary settlements or camps with a clean water supply and sanitation network.

- Raise awareness campaigns among citizens about the importance and benefits of reducing water use (which could cut down the expenses of water to consumers, including immigrants)

- Urge the private sector to contribute to a change in consumer behavior, by encouraging their customers to stand up for water-sustainable products.

The improper sanitation techniques lead to discarding the human waste in open pits or waterways like streams or rivers instead of dealing with it in the proper way, which creates severe health hazards affecting the entire population. Cities shall develop innovative and unconventional sanitation systems for sustainable waste management in different kinds of settlements. Cities as well should engage the private sector with specialized innovators to source solutions, besides raising awareness about safer waste disposal methods.

\subsection{Social Cohesion and Integration}

Formal procedures are generally known to be somehow slow on the level, yet the integration of newcomers depends on these; the more powerful and faster the process, the earlier the integration. As soon as migrants arrive at destination cities, they require access to city facilities and services for which official documents and permits are compulsory. This facilitates their access to legal aid and different services provided such as healthcare, education, banking, and telecommunication. Migrants would find it extremely difficult to integrate within the community and make a good start, unless such services are readily available through a structured and cohesive system.

Successful Arrival cities must benefit from the use of information technology to reach out to their populations, gather information on their profiles and resources to understand their potential, vulnerabilities, and specialties. Collecting data about residents, including migrants and locals, is a key on the pathway to development. Another key point is to integrate newcomers through the accessibility to information (for example through apps, websites or hotlines) to let them identify potential local opportunities [17].

Another smart approach to integrate migrants and make them feel welcome, could rely on a city discourse on community participation, by sensibly listening to immigrants' ideas and their concerns, communicate with them on a regular basis, and support a range of cultural initiatives.

Saunders asserts that it is essential to consider newcomers as fully-fledged immigrants, to provide them with work and accommodate them in regular neighborhoods instead of housing them in former barracks. By doing so, Saunders argues, they will begin to invest their money in the local banks, buy new properties, start their own business and pay taxes, and their children will go on to continue their studies at the local universities. This way they will fully integrate into society, and the society will benefit from them [8].

As a human condition, initially immigrants feel better when concentrated in specific areas, joining their family members, friends, colleagues and/or at least national members of the community. Although such ethnic or racial clusters have even sometimes more economical and inclusion advantages, it raises one of the most challenging and problematic scenarios that cities try to avoid for better integration and for safety and security purposes. It is essential to allocate immigrants in a way that prevents them from creating such clusters. These clusters make integration more difficult for migrants because it gradually turns out to be their permanent place of residence where all people share the same ethnic background and they find it uncomfortable to step out and explore other neighborhoods. They are often starting points and a transition to a healthier life in suburbs or where the majority of the society is. However, the longer the migrants stay at these districts, the harder for them to integrate into other communities [21].

Still thinking on the urban scale, one should recognize 
that on the neighborhood level, public spaces are always critical points for integration. Schools, libraries, gathering spaces, small and cheaper businesses are of higher value for migrant communities than elsewhere [12].

\subsection{Safety and Security}

Immigrants generally, and new comers in specific, are usually more vulnerable than locals since they lack knowledge of local regulations and language, far from their friends or families and unfamiliar with the local community, nor the institutions. Immigrants in many cases lack information about their legal rights, and they usually worry about being deported back to their origin countries in case they violate any of the rules during their stay.

Saunders argues that a crucial step for migrants to feel secure is to grant them the ownership of their homes, so that they have the possibility to upgrade their dwellings, sell it or even buy others. In extreme cases, where newcomers house ghettos or slums, they would still feel integrated as contributors to the economic, political and social structure of the city. He asserts a common theme for Arrival City in which, the sense of ownership and the right to own land are means through which newcomers prove their social, physical, economical and full political existence [8].

Thriving Arrival cities must be able to protect migrants' rights and save them from falling preys to fraud and deception, for example, slave labor, unpaid wages or social security aids, specifically the jobs that require low-skilled labor, such as the housekeeping workforce. Moreover, cites must prevent incidents that result from xenophobic behavior by defining strict polices and regulations to deal with any sort of abuse of migrants whether psychological, physical, sexual or financial. And most importantly, encourage migrants to know their rights and duties in common situations that they may often face.

To ensure this, cities need to [22]:

- Launch dedicated centers (institutional and non-institutional) distributed in the city, where all immigrants shall receive support and vital know their rights.

- Ensure the clarity of laws and regulations to be able to be understood by immigrants modeling.

\section{Conclusion}

The recent Mediterranean migration movements have led to negative socio-economic impacts on Arrival cities. Accordingly, it forced the political decision makers in affected Arrival cities to seek new approaches to be able to host the influxes, or else, the might face a complex scenario of a socio-economic crisis, which may contribute to a territorial conflict. And in Arrival cities where overflowed migration is present, the consequences could be catastrophic. However, there are many opportunities for adaptation and re-urbanization in such cities, which if adapted; one would see the positive narrative for development.

The current migration scenario requires an interdisciplinary approach that involves combining political and socio-economic aspects with the field of urban planning to tackle a contemporary international public opinion issue and promote a healthy adaptation to such man-made disasters. This urges us to define an inclusive term for the future Arrival Cities as "Resilient Cities, which are capable of ingesting immigrations, adapting to the on-going changes and successfully responding to the needs of immigrants. They are often with relatively high attractiveness factor that offers the capacity for re-urbanization, hold opportunities for healthy integration and economic development".

\section{Acknowledgments}

I convey my appreciation to Prof. Dr. José Manuel Pagés Madrigal, Dean of Architecture and Urban Design program at the German University in Cairo, for his constructive suggestions, continuous support, guidance, and advice throughout the research process.

\section{REFERENCES}

[1] Marcus, F. (2017). Good Design for a Bad World. Dezen. Online available from https:/www.dezeen.com/2017/12/1 8/dont-design-shelter-refugees-kilian-kleinschmidt-rene-bo er-good-design-bad-world/

[1] Provoost, M. (2016). The New Urban Agenda -the Perspective of New Towns. International New Town Institute, Rotterdam. Online available from http://www.new towninstitute.org/spip.php?article1161

[2] Girani, S. (2017). Planning cities for migration. Talk, ARUP. Online available from https://www.arup.com/perspectives/p lanning-cities-for-migration

[3] Pepels, N. (2017). Arrival City. Reflection, Master thesis, TU Delft. Online available from https://repository.tudelft.nl /islandora/object/uuid:3a85d1e3-48d7-4549-98c48a65ab04 b308/datastream/OBJ3/download

[4] Colau, A. (2015). Barcelona Refuge City: the Plan. Barcelona Ciutat Refugi. Online available from http://ciutatrefugi.barcelona/en/plan

[5] Ray, B. (2003). The Role of Cities in Immigrant Integration. Migration Information Source, the online journal of the Migration Policy Institute, Washington. Online available from https://www.migrationpolicy.org/article/role-cities-immigra nt-integration 
[6] Charles, A. \& Guna, D. (2017). We need to get better at integrating migrants in our cities. Article, World Economic Forum. Online available from www.weforum.org/agenda/2 017/10/we-need-to-get-better-at-integrating-migrants-into-o ur-cities-here-s-how/

[7] Saunders, D. (2011). Arrival City. How the largest Migration in History is Reshaping our World. Windmill Books, London.

[8] Justice, A. \& Heppner, N. \& Galetti, H. (2017). Physical Characteristics of the Arrival City. Studio Arrival City, Sheffield School of Architecture. Online available from https://studioarrivalcity.wordpress.com/2017/01/16/physica 1- characteristics-of-the-arrival-city/

[9] Elser, O. \& Schmal, P. \& Scheuermann, A. (2016). Making Heimat. Germany, Arrival Country. Deutsches Architekturmuseum (DAM), Frankfurt, 2016.

[10] World Economic Forum (WEF), \& (PwC). (2017). Migration and Its Impacts on Cities. Chapter 3.4, Transportation, p. 128

[11] Helleman, G. (2014). Arrival City. Blog post, Urban Springtime. Online available from http://urbanspringtime.bl ogspot.com/2014/01/arrival-city.html

[12] Mehaffy, M. (2014). 5 Key Themes Emerging From the 'New Science of Cities. Design, CityLab. Online available from

https://www.citylab.com/design/2014/09/5-key-themes-eme rging- from-the-new-science-of-cities/380233/

[13] World Economic Forum (WEF), \& (PwC). (2017). Migration and Its Impacts on Cities. Chapter 3.1, Housing, pp. 116-118

[14] Scheuermann, A. (2016). Building quickly and cheaply, but with a concept: Making a home for refugees in Germany. Arts, Deutsche Welle. Online available from https://www.d w.com/en/building-quickly-and-cheaply-but-with-a-concept -making-a-home-for- refugees-in-germany/a-18932260

[15] World Economic Forum (WEF), \& (PwC). (2017) Migration and Its Impacts on Cities. Chapter 3.2, Education \& Employment, pp. 119-124

[16] The Hague Center for Strategic Studies. (2016). Cities of Arrival: Migrants and Refugees. Online available from https://globalparliamentofmayors.org/wp-content/uploads/2 017/01/Position-Paper-Cities-of-Arrival.pdf

[17] Barber, B. \& Means, J. (2016). The power of collective action: Forging a global role for mayors. Commentary, McKinsey \& Company. Online available from https://www.mckinsey.com/industries/capital-projects-and-i nfrastructure/our-insights/the-power-of-collective-action-fo rging-a-global-role-for-mayors

[18] World Economic Forum (WEF), \& (PwC). (2017.) Migration and Its Impacts on Cities. Chapter 3.3, Health, p. 126

[19] World Economic Forum (WEF), \& (PwC). (2017). Migration and Its Impacts on Cities. Chapter 3.5.1, Water \& Electricity, Chapter 3.6, Sanitation \& Waste, pp. 128-131

[20] International Organization for Migration. (2016). Geneva Conference on Migrants and Cities, 26-27 October 2015. Chapter 5, Managing the social effects of Migration, pp. 67-69

[21] International Organization for Migration. (2016). Geneva Conference on Migrants and Cities, 26-27 October 2015. Chapter 6, Managing migration - local governance, pp. $79-82$ 